Please do not remove this page

RMIT

UNIVERSITY

\title{
Modelling and simulation of national electronic product code network demonstrator project
}

Mo, John

https://researchrepository.rmit.edu.au/esploro/outputs/9921864192301341/filesAndLinks?institution=61RMIT_INST\&index=null

Mo, J. (2009). Modelling and simulation of national electronic product code network demonstrator project. Lecture Notes in Business Information Processing, Vol 22, Designing E-Business Systems. Markets, Services and Network, 60-70. https://doi.org/10.1007/978-3-642-01256-3_6

Document Version: Accepted Manuscript

Published Version: https://doi.org/10.1007/978-3-642-01256-3_6

Repository homepage: https://researchrepository.rmit.edu.au

(c) Springer-Verlag Berlin Heidelberg 2009

Downloaded On 2023/04/27 01:29:23 +1000 
Citation: Mo, J 2009, 'Modelling and simulation of national electronic product code network demonstrator project', in Lecture Notes in Business Information Processing, vol 22, Designing E-Business Systems. Markets, Services and Network, Paris, France, 13 December, 2008.

\title{
Modelling and Simulation of National Electronic Product Code Network Demonstrator Project
}

\author{
John P.T. $\mathrm{Mo}^{1}$ \\ ${ }^{1}$ RMIT University, Melbourne, Australia \\ john.mo@rmit.edu.au
}

\begin{abstract}
The National Electronic Product Code (EPC) Network Demonstrator Project (NDP) was the first large scale consumer goods track and trace investigation in the world using full EPC protocol system for applying RFID technology in supply chains. The NDP demonstrated the methods of sharing information securely using EPC Network, providing authentication to interacting parties, and enhancing the ability to track and trace movement of goods within the entire supply chain involving transactions among multiple enterprise. Due to project constraints, the actual run of the NDP was 3 months only and was unable to consolidate with quantitative results. This paper discusses the modelling and simulation of activities in the NDP in a discrete event simulation environment and provides an estimation of the potential benefits that can be derived from the NDP if it was continued for one whole year.
\end{abstract}

Keywords: EPC Network, National Demonstrator Project, FMCG industry, system simulation, inter-enterprise transactions

\section{Introduction}

The National Electronic Product Code Demonstrator Project (NDP) was the first in the world to implement full Electronic Product Code (EPC) network technology across an entire supply chain for the handling inter-company transactions and movement of goods across company boundaries [1]. The NDP successfully tracked pallets and cartons and had an opportunity to demonstrate the benefits of Radio Frequency Identification (RFID) technology in the fast moving consumer goods (FMCG) supply chain. Sharing the project's learning can save Australian companies time and money [2].

The NDP involved companies from across the FMCG supply chain: Metcash, Gillette, Procter \& Gamble (P\&G), Nugan Estate, Capilano Honey, Visy Industries, Linfox, CHEP, VeriSign, Sun Microsystems and the Australian Food \& Grocery Council (AFGC). The NDP was critical to the participants to gain understanding of the issues in EPC implementation through actual practices. It was also important to small to medium enterprises (SMEs) to learn the technology while observing the actions taken by large industry partners. 
EPC is a low-cost technology, based on passive RFID devices. It is acclaimed as the successor of today's omnipresent bar codes. EPC is the basis of a distributed architecture, called EPC Network, for the automatic identification of objects moving in the supply chain and industrial production applications. Bottani and Rizzi [3] assessed the benefits of EPC Network on fast moving consumer goods (FMCG) supply chain and concluded information flow across all parties was the most important advantage.

The NDP demonstrated the benefits of RFID technology and the use of full stack of EPC Network. It showed how EPC technology could be harnessed for tracking of pallets and cartons through the supply chain [4]. The project demonstrated benefits for all partners within the supply chain, adding to what was already understood about the savings for retailers. The sharing of learning also meant savings in time and money for Australian companies.

In the NDP, detailed use cases were established at each site specifying both the physical process and the information required at each read point. There were totally 15 use cases ( 11 in Gillette, 2 in $P \& G$ and 2 in Metcash) developed by the industry partners of the consortium. Use cases described how the business processes could work with the system (software) and formed the basis for implementing the middleware system in the Demonstrator. According to the use cases, components of EPC Network such as middleware, user interfaces and portal were designed to meet business requirements of the project participants.

To ensure a high probability of success, the consortium decided to simplify the material flow process by limiting the flow to certain product items. After careful consideration of the trading activities in the consortium, 6 industry partners with 9 products were decided for use in the NDP (Table 1).

Table 1. Products used in the EPC process.

\begin{tabular}{ll}
\hline Industry partners & Product \\
\hline CHEP/Visy & Pallet \\
\hline \multirow{2}{*}{ Gillette } & Mach 3 Turbo crt 4's (R1) \\
& Duracell C/T AA4's (R2) \\
\hline \multirow{3}{*}{ P\&G } & PANTENE SMOOTH \& SLEEK SHMP 400ML 2000 \\
& PANTENE SMOOTH \& SLEEK COND 400ML 2750 \\
& PANTENE COLOR REVIVAL SHMP 400ML 2250 \\
& PANTENE COLOR REVIVAL COND 400ML 2750 \\
& METAMUCIL SMOOTH ORANGE 283 GM 1750 \\
& FREBREZE EXTRA STRENGTH 400 ML \\
\hline
\end{tabular}

The NDP achieved the objective of illustrating how the technology could be used in industrial environment. However, it did not develop a quantitative assessment of the benefits. To estimate the real benefit, this research develops a computational model that uses the industrial data to estimate the potential benefits. This paper describes the modelling and simulation analysis and discusses the findings in quantitative terms. 


\section{Scenario analysis by system simulation}

Simulation is a powerful technique for solving a wide variety of problems. Harrison et al [5] tried to promote understanding of simulation methodology by developing an appreciation of its potential contributions to management theory. Molina and Medina [6] analysed design and operation of manufacturing enterprises using simulation tools. Analysis by simulation is to execute the behavior of a system or phenomenon under study in a virtual environment. A system is a collection of distinct objects which interact with each other. In order to study a system, only relevant information will be gathered in the system. Such a collection of pertinent information about a system is called a model of the system.

In our daily life, lots of problems are too complex to solve via exact mathematical analysis, such as weather, traffic jam, aircraft flight, business executive. Firstly, the system itself is too complex or the theory is not yet developed sufficiently. Secondly, there may be too many uncertainties, dynamic interactions between decisions and subsequent events, or interdependencies among variables in the system. Finally, some elaborated laboratory experiments have to be conducted, which are usually expensive and time consuming. Simulation with computer provides another way replacing the laboratory experiments. The analysis process is cheaper and faster and more importantly, efficient.

There are two different types of systems:

1. The systems in which the states change smoothly or continuously with time are called continuous systems. A good example is the simulation analysis by Han and Min [7] on the transmission performance of RFID.

2. The systems in which the states change abruptly at discrete points in time are called discrete systems. For example, Lu and Cheng [8] simulated the role of RFID in a typical manufacturing system and estimated an improvement of more than $8 \%$ was possible. Amini et al [9] presented a simulation study conducted in a regional hospital to investigate tactical and strategic purposes in addition to collateral value quality data generated by this technology.

The complexity and extent of work in the NDP presented similar issues to a pilot research. Quantitative data was difficult to capture due to other business constraints imposed to the experimental environment. This paper describes the research of using real data from the NDP as the basis of simulating the system performance if it were continued for a much longer period. The NDP is a discrete system. Each change in the NDP, such as empty pallet, flat carton inventories, loading and unloading process, customer arrivals, is called an event. Hence, the modelling and simulation of the NDP is a discrete-event simulation.

To illustrate how the NDP is modelled, we provide some background information about the NDP. The material flow process map (Fig. 1) describes the flow of physical items between the consortium partners. The material flow sequence starts from CHEP transporting pallets to P\&G and Gillette. Similarly, pallets are transported from CHEP to Visy. At Gillette, products are made overseas but they are packed in different formats in Australia. Application of EPC is necessary at the carton level when the final form of delivery is made. After application of EPC, products are moved from P\&G/Gillette to Metcash. This will go through the Linfox transport 
system but the movement of goods from Metcash distribution centre (DC) to retail outlets, return of pallets from Metcash DC to CHEP, Visy and suppliers are not traced in NDP model after goods reach Metcash.

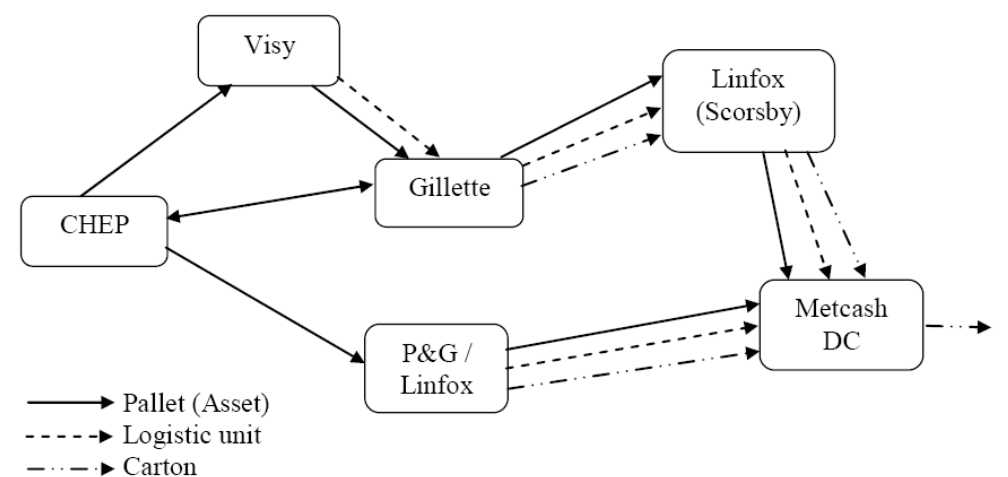

Fig. 1. NDP material flow map.

In addition, tracing of information in the NDP is also important. In the information flow map (Fig. 2), P\&G and Gillette place a request for pallets to CHEP.

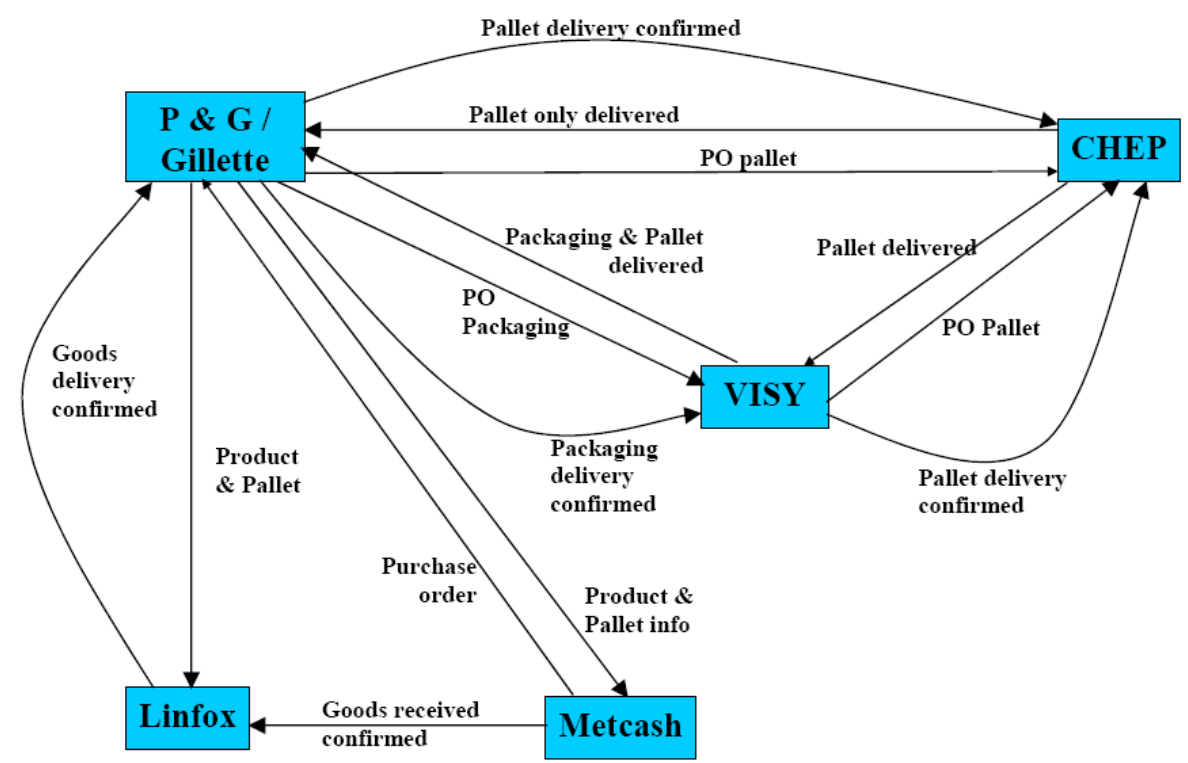

Fig. 2. NDP information flow map.

The start of the individual transaction chain is a purchase order (PO) issued from Metcash to $\mathrm{P} \& \mathrm{G} /$ Gillette. Gillette places a request for flat cartons to Visy. Visy places a request for pallets to CHEP. The suppliers then issue a PO to Visy for the 
required number of cartons, and to CHEP for the required number of pallets. Upon delivery of the pallets and cartons, a corresponding notification will be given to the store person at the receiving company to verify the receipt of goods. Metcash's PO also initiates a series of activities at $\mathrm{P} \& \mathrm{G} /$ Gillette. The goods are packed and loaded on a pallet. The number of carton boxes depends on the quantity ordered. When the order is picked, the products and the pallet are confirmed and the information is sent to Metcash for confirmation and checking. The goods are passed to Linfox where the goods are handled and delivered to Metcash. Once the goods are received, Metcash confirms the receipt of goods through normal documentation.

\section{NDP simulation model}

The simulation system used in this research is ARENA [10]. This simulation system has been used extensively around the world by researchers for discrete process simulation. Creation of the NDP simulation model starts with the Create module, which is named Metcash Inventory Control, the first module in sub model named Metcash Product Inventory Control. When this entity is created, Metcash will check the inventories of all products. If the inventory is higher than a certain level, PO won't be created and the entity will go into Dispose modules. This is one kind of whole life of a flow from Create to Dispose.

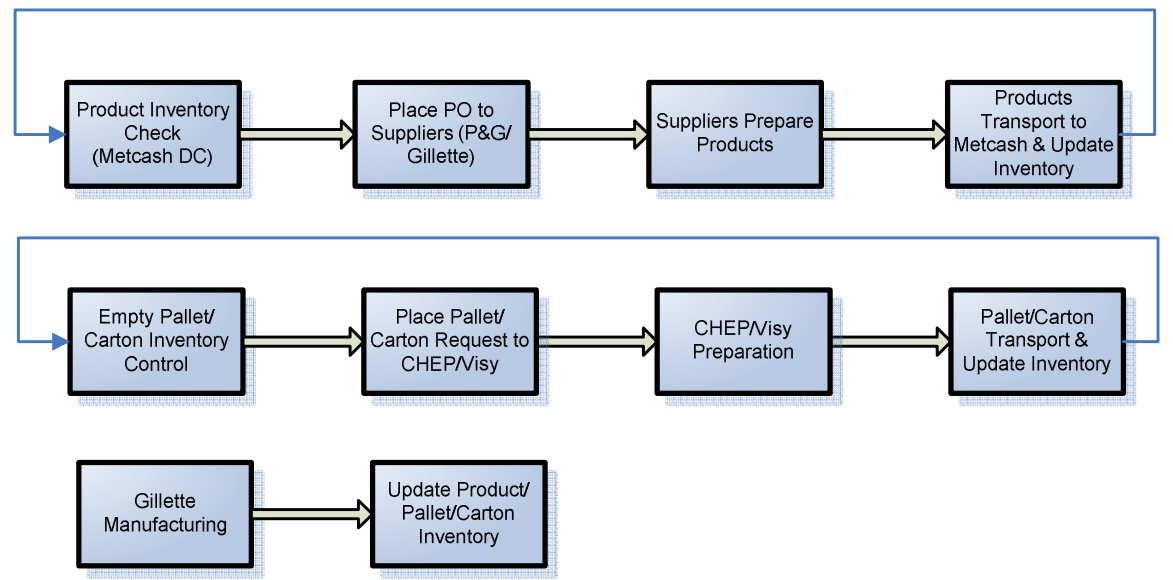

Fig. 3. Basic work flow in NDP simulation model.

If the inventory is lower than a certain level, a PO will be created and placed to the corresponding suppliers. After PO is received by supplier, plenty of flowchart modules will simulate how products are packed, wrapped, transferred, loaded and finally transported to Metcash DC. Attributes about order and products, and variables about inventory will be updated and when products are stored. This flow will be concluded by Dispose modules. 
The establishment of NDP simulation model (Fig. 3) is based on the basic work flow as in Fig. 1 and the information flow in Fig. 2. At the beginning of each day, Metcash DC checks inventory (we denote as $I(t)$, where $t$ is time) to decide whether to place an order. If the inventory level is less than a constant $s$, Metcash DC orders "up to" another constant $S$. What this means is that Metcash DC place a PO so that, if they were to arrive instantly, the inventory level would pop up to exactly $S$.

Therefore, if $I(t)<s$, Metcash orders $S-I(t)$ items in a PO; if $I(t) \geq s$, Metcash does nothing. This process of checking will occur again on the next day. We called this policy $(s, S)$ inventory models. P\&G and Gillette also use $(s, S)$ inventory model to control the pallet/carton inventories. PO or requests are issued by suppliers and goods are prepared. When goods arrive at destinations, corresponding inventories will be updated immediately.

Table 2. NDP simulation modules.

\begin{tabular}{|c|c|c|}
\hline Module & Module & Product \\
\hline \multirow[t]{3}{*}{$\begin{array}{l}\text { Metcash } \\
\text { DC }\end{array}$} & $\begin{array}{l}\text { Metcash receiving } \\
\text { process }\end{array}$ & $\begin{array}{l}\text { To receive products from } \mathrm{P} \& \mathrm{G} \text { and Gillette, transport them } \\
\text { to designated areas }\end{array}$ \\
\hline & $\begin{array}{l}\text { Metcash product } \\
\text { inventory control }\end{array}$ & $\begin{array}{l}\text { To monitor and take actions controlling inventory level at } \\
\text { Metcash }\end{array}$ \\
\hline & $\begin{array}{l}\text { Metcash dispatch } \\
\text { process }\end{array}$ & $\begin{array}{l}\text { NDP simulation model doesn't keep trace the pallets and } \\
\text { cartons, so the sub-model just describes the customer } \\
\text { arriving with some demand attributes, and update the } \\
\text { inventories after the products are dispatched. }\end{array}$ \\
\hline \multirow[t]{4}{*}{ Gillette } & $\begin{array}{l}\text { Gillette } \\
\text { manufacturing }\end{array}$ & $\begin{array}{l}\text { There are two series of products in the Gillette plant. They } \\
\text { are produced as small packs, but entities in the simulation } \\
\text { model are pallet units. }\end{array}$ \\
\hline & $\begin{array}{l}\text { Gillette pack and } \\
\text { wrap Pallets for } \\
\text { customer order }\end{array}$ & $\begin{array}{l}\text { It is a complicated function in the simulation model, as } \\
\text { there are two important activities: packing and wrapping, } \\
\text { and one logic control are merged. }\end{array}$ \\
\hline & $\begin{array}{l}\text { Gillette flat cartons } \\
\text { receiving and } \\
\text { empty pallets } \\
\text { returning process }\end{array}$ & $\begin{array}{l}\text { This is a simple function that flat cartons or empty pallets } \\
\text { arrive at Gillette are transferred as stacks and pallets } \\
\text { respectively. }\end{array}$ \\
\hline & $\begin{array}{l}\text { Gillette pallet and } \\
\text { carton request }\end{array}$ & $\begin{array}{l}\text { This is a logic control for Gillette requesting empty pallets } \\
\text { and flat cartons, which is similar to Metcash product } \\
\text { inventory control. }\end{array}$ \\
\hline \multirow[t]{3}{*}{$P \& G$} & $\begin{array}{l}\mathrm{P} \& \mathrm{G} \text { pallets } \\
\text { receiving process }\end{array}$ & $\begin{array}{l}\text { Pallets are unloaded, transferred through reader gantry. } \\
\text { Inventory will be updated automatically and the pallet } \\
\text { request situation will be changed. }\end{array}$ \\
\hline & P\&G use cases & This function simulates the pick and pack use case at P\&G. \\
\hline & P\&G pallet request & $\begin{array}{l}\text { This is a logic control of }(s, S) \text { inventory model for } \mathrm{P} \& \mathrm{G} \\
\text { placing request of empty pallets, which is similar to Gillette } \\
\text { pallet request. }\end{array}$ \\
\hline CHEP & CHEP use cases & $\begin{array}{l}\text { This function is to prepare empty pallets and transport them } \\
\text { to customers }\end{array}$ \\
\hline Visy & Visy use cases & $\begin{array}{l}\text { This is a logic control of }(s, S) \text { inventory model for Visy } \\
\text { placing request of empty pallets. Visy checks empty pallet } \\
\text { inventory once a day. }\end{array}$ \\
\hline
\end{tabular}


Metcash's PO initiates most of activities at P\&G, Gillette CHEP and Visy. Only Gillette manufacturing is independent from Metcash's PO. However, Gillette manufacturing's activities are based on the sales forecast and the production quantity will be based on the PO quantity rather than inventory.

The NDP simulation model is further separated into five sub models. Each sub model represents a consortium member and has several functions for different work. All sub models and functions are listed in Table 2.

\section{Parameters used in simulation}

Before the simulation is set to run, there are some important parameters to be set up. The simulation time is 360 days. Initial value of variables should be given before simulation runs, because they describe the situation at the time when the simulation runs. We assume all empty pallet and flat carton request situation and PO situation are 0 , which means there is no request or PO at the start, irrespective of whether the inventories are lower than level $s$. All the initial values of inventories are listed in Table 3.

In order to quantify the benefits of NDP, several KPIs should be defined before simulation runs. There are two phases to evaluate the authenticity. The first phase is the time for each Process and Route. The primary data about time is based on the image transcription of NDP. Therefore, there is no doubt to the authenticity of time. The second phase is logic control of inventories. Most of activities start from inventory control. The inventory model $(s, S)$ is used in every inventory and the focal point is to set up $s$ and $S$ properly. Shortage may happen because of too small $s$, and overstock may happen because of too large $S$. The $S-s$ controls the frequency of placing orders or requests. If the frequency is too high, it will cause the rising of ordering cost.

Table 3. Initial values of variables.

\begin{tabular}{lc}
\hline Variable name & Initial value \\
\hline P\&G empty pallet inventory & 30 \\
Gillette empty pallet inventory & 100 \\
Gillette empty carton inventory & 40 \\
Visy empty pallet inventory & 50 \\
P\&G product inventory & 30 \\
Gillette Mach3 inventory & 15 \\
Gillette AA4 inventory & 15 \\
\hline
\end{tabular}

To evaluate effectiveness of EPC technology, several time values are accumulated during simulation. Processing time means the time when a PO is placed until the required products are received. It includes delays at a value added process, wait time in a queue and transfer time. The application of EPC will increase time of some process, such as placing tags on cartons, pushing cartons through gravity feedline and scanning tags on pick faces, etc. On the other hand, it will decrease time of some other process, such as administration work after products and pallet arriving, 
documents check, etc. It is not necessary to calculate the time for each detailed process, but the processing time including the value added delay time and wait time can indicate the change of the efficiency of the system.

The cost of labour varies slightly at different locations in the country. The actual labour cost per hour is used as shown in Table 4.

Table 4. Labour cost list.

\begin{tabular}{lc}
\hline Company & Labour cost/ hour \\
\hline CHEP & $\$ 32$ \\
P\&G & $\$ 28$ \\
Gillette & $\$ 25$ \\
Visy & $\$ 23$ \\
Metcash & $\$ 31$ \\
\hline
\end{tabular}

\section{Analysis of results}

The main measure to assess the authenticity of the simulation is to examine the three plots: P\&G Product Inventory, Gillette AA4 Inventory and Gillette Mach3 Inventory. The inventories rebound between proposed levels and there are rare shortages or overstocks. The plots are shown in Fig. 4, 5 and 6. 


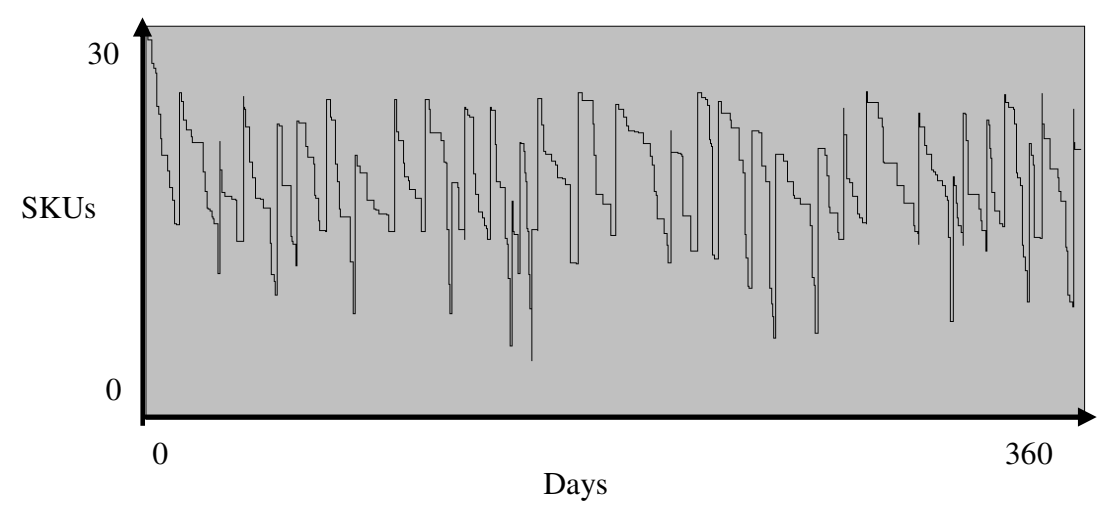

Fig. 4. The $P \& G$ product inventory plot.

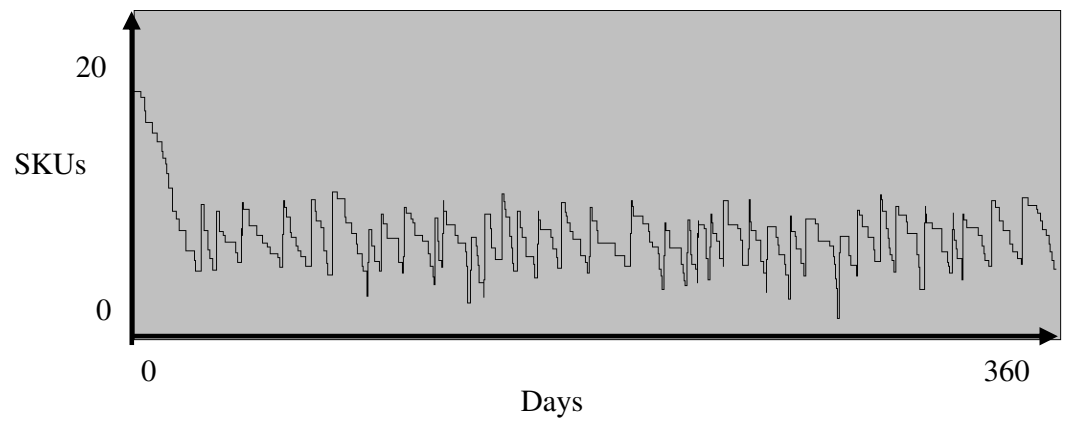

Fig. 5. The Gillette AA4 inventory plot.

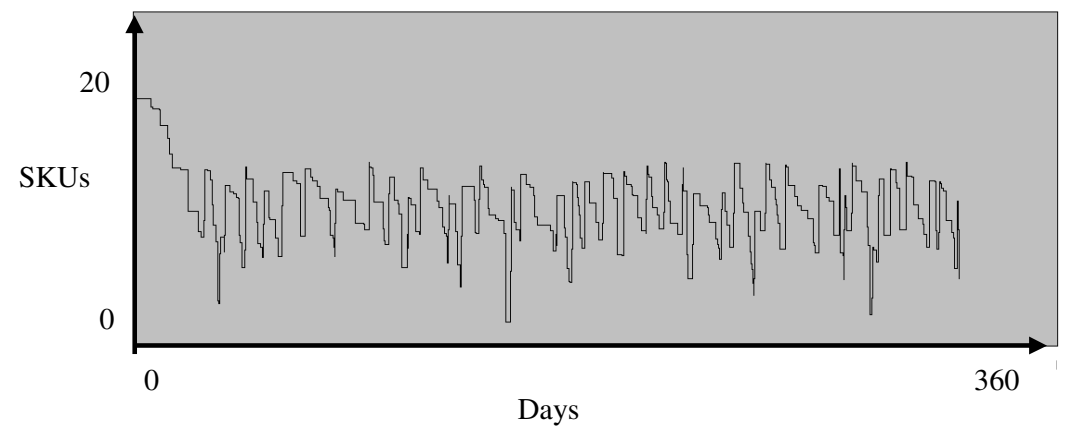

Fig. 6. The Gillette Mach3 inventory plot.

We calculate PO Processing Time in days by the function: 
where:

- VA Time means value added time, which is accumulated when an entity incurs a delay at a value added process.

- NVA Time means non-value added time, which is accumulated when the entity incurs a delay at a non-value added process.

- Wait time is accumulated when the entity incurs a delay at a process whose allocation has been designated as wait, or when the entity resides in a queue until the entity exits the queue.

- Transfer Time is accumulated when the entity incurs a delay at a process whose allocation has been designated as transfer. By default, all time spent using material handling from the Advanced Transfer panel (a conveyor or transporter) is specified as transfer

The Average PO Processing Time, VA time and Wait Time are then computed from the simulation as shown in Table 5. Table 6 shows the resource implication:

Table 5. PO processing time (days).

\begin{tabular}{lcccccc}
\hline & $\begin{array}{c}\text { Average } \\
\text { PO } \\
\text { processing } \\
\text { time (days) }\end{array}$ & $\begin{array}{c}\text { Accumu- } \\
\text { lated total } \\
\text { PO } \\
\text { processing } \\
\text { time (days) }\end{array}$ & $\begin{array}{c}\text { Average } \\
\text { VA time } \\
\text { (days) }\end{array}$ & $\begin{array}{c}\text { Accumu- } \\
\text { lated VA } \\
\text { time (days) }\end{array}$ & $\begin{array}{c}\text { Average } \\
\text { wait time } \\
\text { (days) }\end{array}$ & $\begin{array}{c}\text { Accumu- } \\
\text { lated wait } \\
\text { time (days) }\end{array}$ \\
\hline AA4 PO & 1.244 & 242.619 & 0.0685 & 13.365 & 0.157 & 30.635 \\
Mach3 PO & 1.241 & 323.901 & 0.0535 & 13.973 & 0.147 & 38.236 \\
P\&G PO & 1.798 & 61.118 & 0.5579 & 18.969 & 0.000049 & 0.00167 \\
\hline
\end{tabular}

Table 6. Total labour cost.

\begin{tabular}{lcccc}
\hline & $\begin{array}{c}\text { Average } \\
\text { number } \\
\text { busy (days) }\end{array}$ & $\begin{array}{c}\text { Total busy } \\
\text { time (days) }\end{array}$ & Daily pay & Sum \\
\hline CHEP admin & 0.00688 & 2.47764 & $\$ 256$ & $\$ 634$ \\
CHEP labour & 0.00796 & 2.86654 & $\$ 256$ & $\$ 734$ \\
Gillette admin & 0.00556 & 2.00012 & $\$ 200$ & $\$ 400$ \\
Gillette labour & 2.5669 & 924.084 & $\$ 200$ & $\$ 184,817$ \\
Metcash labour & 0.00369 & 1.32761 & $\$ 248$ & $\$ 329$ \\
P\&G admin & 0.00179 & 0.64445 & $\$ 224$ & $\$ 144$ \\
P\&G labour & 0.04729 & 17.0248 & $\$ 224$ & $\$ 3,814$ \\
Visy admin & 0.00471 & 1.69695 & $\$ 184$ & $\$ 312$ \\
Visy labour & 0.01471 & 5.29593 & $\$ 184$ & $\$ 974$ \\
\hline Total cost & & & & $\$ 192,158$ \\
\hline
\end{tabular}

The labour cost can then be evaluated by the function: 
The saving of $\$ 192,158$ is the overall labour cost savings if the NDP continues for a year. Other costs such as overhead and materials costs are not included. Therefore, it only represents a tiny section of the potential savings of the supply chain. Given that there are thousands of products handled by the consortium companies, the savings will be significant if the EPC technology is rolled out to the whole supply chain.

\section{Conclusion}

This paper gives the background of NDP and discusses some basic concepts of EPC. The NDP was executed for 3 months due to budget and resources constraints. Very limited quantitative conclusion could be drawn from the pilot study. Based on the NDP experience and the information available, the NDP is modelled in a discrete event simulation system. The computer model is simulated for analysing the potential performance of the NDP if it was run for a longer period than it was.

The NDP simulation model runs successfully and reports about entities, queues and resources were exported. According to the KPIs, relevant data during the simulation run was collected including plots and tables. PO Processing Time and Labour Cost were quantified. The simulation result shows that a direct labour cost saving of $\$ 192,158$ could be achieved if the NDP was run for one whole year. If overhead and other costs are included in the estimation, and if the EPC technology is rolled out to the whole supply chain, the savings will be substantial.

\section{References}

1. GS1 Australia, CSIRO: EPC Network ${ }^{\mathrm{TM}}$ Australia Demonstrator Project Report. Available on request from http://www.gs1au.org/. (2006)

2. Attaran, M: RFID: an enabler of supply chain operations. Supply Chain Management: An International Journal. 12:4, 249-257 (2007)

3. Bottani, E., Rizzi, A.: Economical assessment of the impact of RFID technology and EPC system on the fast-moving consumer goods supply chain. International Journal of Production Economics. 112:2, 548-569 (2008)

4. Mo, J.P.T.: Development of a national electronic product code network for the tracking of fast moving consumer goods. Int. J. Enterprise Network Management. 2:1, 25-46 (2008)

5. Harrison, J. Richard, Carroll, Glenn R., Carley, Kathleen M.: Simulation Modelling in Organisational and Management Research. Academy of Management Review. 32:4, 12291245 (2007)

6. Molina, A., Medina, V.: Application of enterprise models and simulation tools for the evaluation of the impact of best manufacturing practices implementation. Annual Reviews In Control. 27:2, 221-228 (2003)

7. Han, Y., Min, H.: System Modelling and Simulation of RFID. Auto-ID Labs Research Workshop, Zurich, Switzerland. 23-24 September (2004) 
8. Lu, B., Cheng, K.: Modelling and simulation on an RFID based manufacturing system. 4th Innovative Production Machines and Systems Virtual International Conference IPROMS 2008. (Eds.) D.T. Pham, E.E. Eldukhri, A.J.Soroka. Internet Conference on http://conference.iproms.org/ (2008)

9. Amini, M., Otondo, R.F., Janz, B.D., Pitts, M.G.: Simulation Modeling and Analysis: A Collateral Application and Exposition of RFID Technology. Production and Operations Management. 16:5, 586-598 (2007)

10. Kelton, W.D., Sadowski, R.P., Sturrock, D.T.: Simulation with Arena. Pub. McGraw-Hill, 4th edition, ISBN 9780071286046 (2007) 